\title{
Long-term survival of corneal transplants and visual outcomes among private patients of corneal surgeons in Metropolitan Manila (the Philippines)
}

\author{
David FF Chan and Dominga B. Padilla \\ Department of Ophthalmology and Visual Sciences. Philippine General Hospital, \\ University of the Philippines Manila, Manila, Philippines
}

\begin{abstract}
Purpose: There are currently no published studies on the outcomes of keratoplasty in the Philippines. This study aimed to report graft survival rates at years one, three and five after surgery, visual outcomes, and causes of graft failure among private patients of corneal surgeons in Metropolitan Manila receiving tissue from a single local eye bank in the period 2008-2012.

Design: Retrospective cohort, multi-center study.

Methods:

Population: Private patients of Metro Manila corneal surgeons, receiving tissue from the Santa Lucia International Eye Bank of Manila in 2008-2012. Two hundred and forty-one of 593 yielded sufficiently complete data sets.

Procedure: Donor and tissue characteristics, preoperative and latest follow-up characteristics/clinical findings were retrieved and processed. Data from the eye bank was merged with follow-up data from surgeons submitted March-October 2014.

Main outcome measures: Survival rates at one, three and five years; best-corrected visual acuity as of latest follow-up; causes of failure.

Results: Interval between surgery and most recent follow-up (number of patients) at less than one year $=41$; at least one year but less than three years $=112$; at least three years but less than five years $=61$, and at least five years $=27$. One-year survival: $90.4 \%$; three-year: 71.5\%; five-year: $\sim 52.7 \%$. Overall, $43.5 \%$ had postoperative best corrected visual acuity of $20 / 50$ or better, and $25 \%$ counting fingers or worse, with variations across diagnoses.

Conclusion: Although small in sample size and response rate, survival trends parallel studies with larger populations elsewhere. Specific trends like favorable survival in keratoconus were consistent. Indications for surgery have changed little since 2005, but regraft has become the most common indication. Further data collection and completion are required for multivariate analysis on factors regarding survival. Uncontrolled intraocular pressure, Inflammation, infection, trauma, and poor adherence to medications are among the identified reasons for failure.
\end{abstract}

Keywords: keratoplasty, transplant, survival, Philippines

\section{Introduction}

Corneal blindness is estimated to be the second most prevalent cause of bilateral blindness in less-developed countries. However, its true prevalence is difficult

Correspondence: David Francis Fullon Chan.

E-mail: dvidffc@gmail.com. 
to assess because epidemiological data is limited and classification schemes are complicated..$^{1-7}$ In the Philippines, it is the fifth most prevalent cause of bilateral blindness, but as in the rest of the world, its actual prevalence may be much more due to shared difficulties in accurate classification. . $^{80,16 .}$.

While the profound difference between the burden of binocular and monocular blindness is obvious, vision loss in one eye still represents a significant departure from the optimal state. Factors and etiologies that bear risk for corneal blindness have yet to be eliminated in the present day and age. The importance therefore of optimizing the predominant treatment of choice, keratoplasty, remains. The urgency of this endeavor is heightened by many additional constraints yet to be resolved - the absence of universally-approved synthetic materials, scarcity of tissue worldwide, permanent graft survival not being the rule, and the lack of active and constantly updated registries to report outcomes in different populations. ${ }^{10-15,17-20}$

Local outcome measures have not been reported, and save for larger and more developed populations - Singapore, China, India - the literature offers little more data for Asian populations. ${ }^{12}$ Filipino surgeons have been able to render the intervention for more than a decade now, owing to the establishment in 1995 of the Santa Lucia International Eye Bank of Manila (SLIEBM). Save for very small numbers of tissue processed by an eye bank in the city of Cebu, the SLIEBM has been the dominant source graft tissue in the Philippines ever since. It maintains operating and tissue evaluation standards acceptable to the Association of Eye Banks of Asia; each tissue released is seen and approved by both a trained technician and a cornea-external disease subspecialist.

This study, therefore, was interested in corneal transplant survival rates, postoperative visual acuity, and causes of graft failure in the capital of this developing, middle-income Asian nation. Outcomes of penetrating keratoplasty using optical corneal grafts from the single local eye bank implanted in private patients of Metropolitan Manila cornea surgeons were examined. Survival rates at one, three and five years post-surgery, and, best-corrected visual acuities achieved in the most recent follow-up were quantified. Factors associated with failure were described.

\section{Materials and Methods}

\section{Study design:}

Retrospective cohort study, multi-center. Follow-up forms were sent to all corneal surgeons (members of the local cornea and external disease subspecialty society) who per eye bank data, conducted keratoplasty using optical donor tissue in the years 2008-2012 within Metropolitan Manila. Survival status, visual acuity, and postoperative interventions and complications were inquired. Surgeries were carried out in different hospitals, hence the multi-center nature of the study.

\section{Participants, inclusion and exclusion criteria:}

Only private patients undergoing penetrating keratoplasty were included. All patients that underwent surgery with post-operative data available for all of them 
at one, three and five years were included. The remaining patients with follow-up data missing were excluded. No exclusion was made based on age, race, or any demographic characteristic of either donor or recipient.

\section{Main outcome measures:}

Graft survival rates at one, three and five years, best corrected visual acuity and causes of graft failure.

\section{Added descriptive statistics:}

We also tabulated the indications for surgery, survival rates overall and per diagnosis, visual acuity postoperative, and reasons for failure.

\section{Data and statistical analyses:}

Kaplan-Meier survival analysis was used for survival-related calculations. Other measures were tabulated and summarized.

\section{Ethics board approval:}

Philippine General Hospital Expanded Hospital Research Office (ethics board) approval was granted October 10, 2013 ((OVS) 2013-295-01 Version No. 1). All conventions and regulations pertaining to donor and patient information were re-examined and applied. The principles of the Declaration of Helsinki were adhered to. All data was handled with privacy and confidentiality, with efforts taken to eliminate detail in outputs that would permit reconstruction of identities.

\section{Results}

Five hundred and ninety-three corneas for use in private cases were distributed during the period 2008 to 2012. Two hundred and fifty-two forms were returned from 25 of 50 surgeons (50\%), and after exclusion for deficiencies in data, 241 were included (40.64\%). The distribution of surgeries per surgeon yielded an average of 9.64 per surgeon. The surgeon with the greatest number of cases had 42 , and 16 surgeons carried out less than ten surgeries. Owing to deficiencies in records, data was absent on sex, age and pre-operative best corrected visual acuities for more than two thirds of the patients.

Two hundred and twenty-five cases were full-thickness penetrating keratoplasty (PK) only, 15 cases had the added steps of lens extraction and intraocular lens implantation, and one case involved only lens extraction and anterior vitrectomy with the PK.

Interval between surgery and most recent follow-up (number of patients) at less than one year $=41$, at least one year but less than three years $=112$, at least three years but less than five years $=61$, and at least five years $=27$.

Overall one-year survival was $90.4 \%$, three-year was $71.5 \%$, and five-year was $52.7 \%$ (Fig. 1).

Regraft, pseudophakic bullous keratopathy (PBK), microbial keratitis, corneal scar, and Fuch's Endothelial Dystrophy were the five most common diagnoses (Table 1). These yielded survival rates at year five as low as $32 \%$ and as high as $61 \%$. 


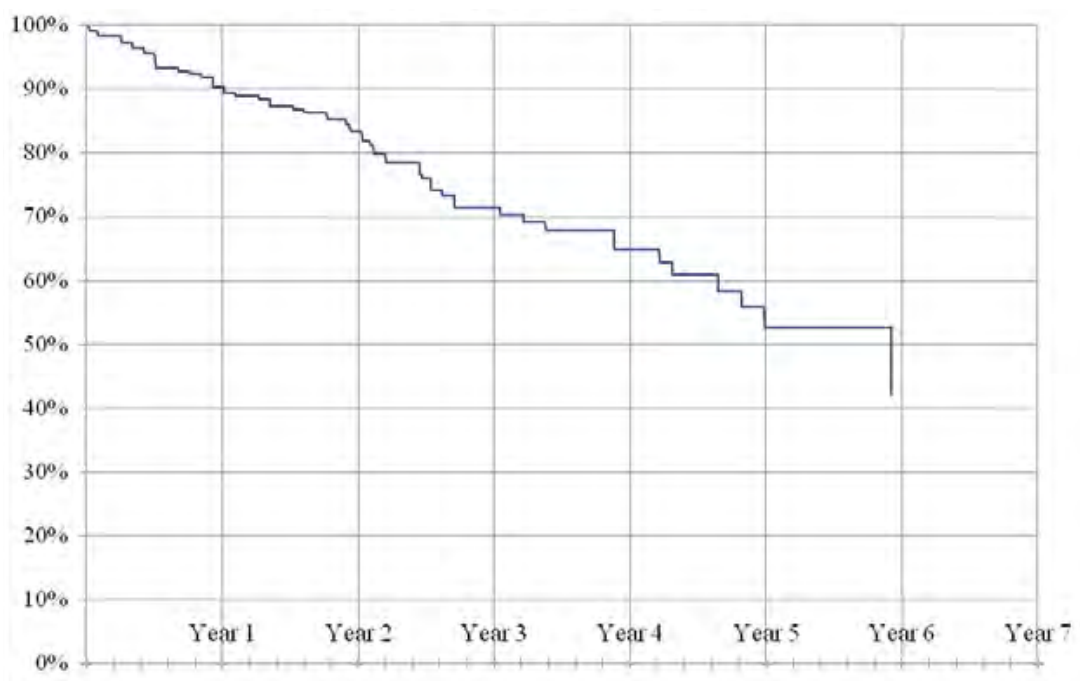

Fig. 1. Kaplan Meier Plot

\begin{tabular}{|l|r|r|r|r|r|}
\hline \multicolumn{1}{|c|}{ Diagnosis } & Year 1 & Year 2 & Year 3 & Year 4 & Year 5 \\
\hline 1. Regraft $(\mathrm{n}=66)$ & $88.7 \%$ & $86.7 \%$ & $81.1 \%$ & $72.4 \%$ & $52.2 \%$ \\
\hline 2. Pseudophakic Bullous Keratopathy (58) & $94.3 \%$ & $92.3 \%$ & $82.3 \%$ & $71.3 \%$ & $61.1 \%$ \\
\hline 3. Corneal Scar (28) & $91.5 \%$ & $70.7 \%$ & $43.2 \%$ & $32.4 \%$ & $32.4 \%$ \\
\hline 4. Microbial Keratitis (23) & $81.7 \%$ & $65.6 \%$ & $52.4 \%$ & $52.4 \%$ & $52.4 \%$ \\
\hline 5. Fuch's Endothelial Dystrophy (22) & $94.7 \%$ & $78.3 \%$ & $71.8 \%$ & $71.8 \%$ & $47.8 \%$ \\
\hline
\end{tabular}

Table 1. Survival Rates of the top 5 diagnoses at yearly intervals.

Of the patients, $43.5 \%$ had best corrected postoperative visual acuity of $20 / 50$ (0.4) or better. However, $39.4 \%$ had postoperative vision of $20 / 200$ or worse $(0.1$ or less), with $25 \%$ at counting fingers or worse (Fig. 2).

Rejection (4.9\% of all grafts), uncontrolled intraocular pressure and endothelial failure were the top-listed reasons for failure observed in the postoperative period. A host of other phenomena have also been observed, with patient related factors

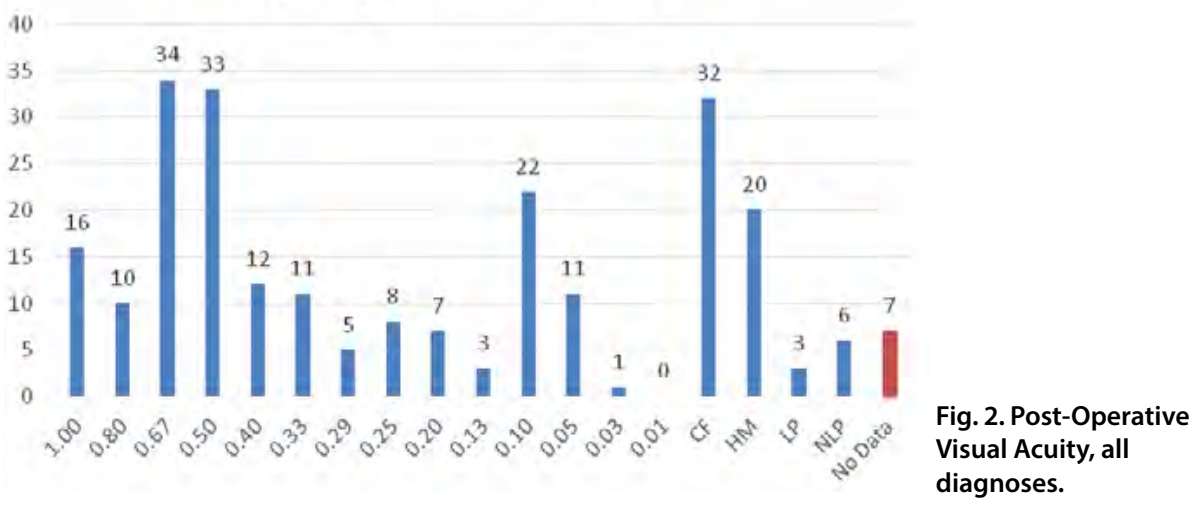


of poor follow-up and poor compliance to medication cited seven times (Table 2).

\begin{tabular}{|l|c|}
\hline \multicolumn{1}{|c|}{ Reason for Failure } & No. Patients \\
\hline Uncontrolled Intraocular Pressure & 13 \\
\hline Rejection & 12 \\
\hline Not Stated & 12 \\
\hline Endothelial Failure & 10 \\
\hline Poor Follow-Up & 5 \\
\hline Recurrence Of Infection & 3 \\
\hline Infection & 2 \\
\hline Poor Compliance To Meds & 2 \\
\hline Chronic Hypotony & 2 \\
\hline Graft Melt & 2 \\
\hline Ocular Surface Disease & 1 \\
\hline Following Eye Surgery & 1 \\
\hline Edema Following Systemic Illness & 1 \\
\hline Silicone Oil Endotheliopathy & 1 \\
\hline Graft Opacity & 1 \\
\hline Trauma & 1 \\
\hline Neurotrophic Ulcer & 1 \\
\hline Decompensated Corneal Graft & 1 \\
\hline
\end{tabular}

Table 2. Reasons for failure post-op, as reported by surgeons.

\section{Discussion}

Results from this Filipino population of keratoplasty patients contribute to a number of study areas. While it is the first effort at reporting local outcomes, it contributes to knowledge for both the Asian population and the developing world. Uniquely, it demonstrates outcomes for private patients of a community of surgeons who have increasing expertise with keratoplasty, but perhaps relatively less experience when compared to the developed world.

The top indication for surgery in the time period was regraft, which accounts for one-fourth of the cohort. This may imply the possibility of poorer survival-to-date if the cohort were to include all past recipients, considering (1) a likely 'learning curve' period in the early years of keratoplasty in the Philippines; (2) refinements in medical technologies and techniques over those same years; and (3) the exclusion of charity/service patients. These may be the factors behind the drop to $52 \%$ survival at year five. Strength can be lent to this hypothesis by expanding the cohort's size.

This study was limited to private patients in the Metropolitan Manila area for ease of securing records. The ratio of private to service cases have varied per year; for example, the year 2013 saw 70\% of cases private, and 30\% service. For the year 
2012 , the proportion was $49 \%$ private and $51 \%$ service. The possibility that compliance and access to care of these patients were better than that of charity/service patients - and therefore would demonstrate the better local outcomes - must be considered.

With these possible limitations in mind, we note that overall, at least until year three, the population studied still yielded survival rates that are not drastically lower compared to the latest results from elsewhere (albeit gathered in the five to ten years prior). Notably, four of the top five most common indications mirrored that of our Asian comparator, Singapore. ${ }^{12}$ Although not tested for significance, similar if not higher survival rates were observed in our sample. Perfect survival as of the five-year mark for 11 grafts done for keratoconus locally is in conformity with the global experience. ${ }^{21,22}$ The strength of these figures however may be somewhat weakened by the lack of uniformity in terms of interval between surgery and most recent follow-up.

Tan et al. ${ }^{12}$ even then did point out how direct comparisons across populations may be unwieldy if only because similarity of clinical parameters was not established. We feel, however, that the absence of gross dissimilarities at least suggests that there may be a common experience/slope of degeneration and failure, across any dissimilarities in context and environment. Certainly, there will be areas of divergence; the survival rates of $18.3 \%$ in Singapore, ${ }^{12} 64 \%$ in Italy ${ }^{18}$ and $53.5 \%$ in Australia $^{13}$ at five years for regraft compared to ours of $52.2 \%$ is one figure that seems to invite investigation. Examination of indications for the first transplant, standards for judging survival, and any difference in technique or care at all points - from harvesting, through to surgery and the postoperative period - may be in order for this.

Studies in less-developed Asian nations s,12 $^{9}$ the Philippines included - frequently highlight the high occurrence of infectious keratitis. Accompanying characteristics already regarded as 'high-risk', particularly of inflammation and vascularization, are also mentioned. The varied insults reported as reasons for failure in this present study seem to agree with this perspective. The peculiarly high year-five survival rate of $74 \%$ for patients with infectious keratitis may also thus deserve further examination. Issues of classification may arise here as well, as the diagnosis of scar (which has lower survival rates) may include previous infectious or inflammatory states.

Lack of data to investigate risk/survival factors is a clear shortcoming of this present investigation; easily verified characteristics regarding the donor, tissue, and recipient would permit more extensive conclusions. Its importance is highlighted when we consider the areas of divergence already observed across populations. Fasolo et al. concluded from their Italian sample that indication for surgery is the primary determinant of long-term maintenance of graft clarity, with associations noted only with lens status, and previous inflammation or infection..$^{18}$ Tan et al.'s Singaporean study meanwhile also identified recipient age and gender, and donor endothelial cell count as factors impacting survival significantly. ${ }^{2}$ These, along with a number of other variables - including tissue death-to-preservation time, surgeon workload, recipient comorbidities - can be secured in our sample and subsequently 
processed to permit comparison with global trends. In terms also of final visual acuity, rates of improvement are not reported as many surgeons failed to report preoperative vision. The report of postoperative VA's, therefore, serves only as a rough description of functional outcomes.

Be that as it may, this preliminary investigation for our unique sample - developing world patients but possibly 'optimized' owing to private case status, with comparatively rapid adaptation of therapeutic techniques by local surgeons - reveals that survival rates approximating the experience elsewhere are being achieved. Further contributions to describing the local/regional experience, as well as to confirm factors for survival would be made possible by mining more data and expanding the dataset. In this era when the demand for this resource-heavy intervention persists, it is clearly an effort that deserves a follow-through, and that must be sustained.

\section{Acknowledgments}

The staff of the Santa Lucia International Eye Bank of Manila.

Cynthia Pedroso Cordero, MSPH, MMedStat, Professor of Biostatistics, Department of Clinical Epidemiology, College of Medicine, University of the Philippines Manila, Ms. Denise Valerie Silfverberg and Mr. Francis James Singun, serving as statistics consultants.

Nilo Vincent DG FlorCruz II MD and Rolando Enrique D. Domingo MD for conceptualization and technical review.

\section{References}

1. Oliva MS, Schottman T, Gulati M. Turning the tide of corneal blindness. Indian J Ophthalmol 2012;60:423-427.

2. World Health Assembly Document A62/7: Action plan for the prevention of avoidable blindness and visual impairment 2009-2013, pp. 7-17. Geneva: WHO Press 2009.

3. Pascolini D, Mariotti SP. Global estimates of visual impairment 2010. Br J Ophthalmol 2012;96:614-618.

4. Resnikoff S, Pascolini D, Etya'ale D, et al. Global data on visual impairment in the year 2002. Bull World Health Organ 2002;82:844-851.

5. Dandona R, Dandona L. Corneal blindness in a southern Indian population: Need for health promotion strategies. Br J Ophthalmol 2003;87:133-141.

6. Dandona L, Dandona R, Naduvilath TJ, et al. Is current eye-care-policy focus almost exclusively on cataract adequate to deal with blindness in India? Lancet 1998;351:1312-1316.

7. Lewallan S, Courtright P. Blindness in Africa: Present situation and future needs. Br J Ophthalmol 2001;85:897-903.

8. Cubillan LDP, Olivar-Santos. Third national survey on blindness. Philipp J Ophthalmol 2005;30(3):100-114.

9. Padilla MDB, Eltanal-Pascual MAT. Indications for penetrating keratoplasty in the Philippines. Philipp J Ophthalmol 2005;30(1):148-152.

10. Moffatt SL, Cartwegith VA, Stumpf TH. Centennial review of corneal transplantation. Clin Exper Ophthalmol 2005;33(6):642-657.

11. Claesson M, Armitage WJ. Ten-year follow-up of graft survival and visual outcome after penetrating keratoplasty in Sweden. Cornea 2009;28(10):1124-1129.

12. Tan DTH, Janardhanan $P$, Zhou H, et al. Penetrating Keratoplasty in Asian Eyes: The Singapore Corneal Transplant Study. Ophthalmology 2008;115(6):975-982.e1. 
13. Williams KA, Lowe MT, Bartlett CM, et al. The Australian Corneal Graft Registry 2007 Report. Bedford Park: Flinders University Press 2007.

14. Fagerholm $P$, et al. A biosynthetic alternative to human donor tissue for inducing corneal regeneration: 24-month follow-up of a phase 1 clinical study. Sci Transl Med 2010;25;2(46):46ra61.

15. Gomaa A, Comyn O, Liu C. Keratoprostheses in clinical practice - a review. Clin Exper Ophthalmol 2010;38:211-224.

16. Whitcher JP, Srinivasan M, Upadhyay, MP. Corneal blindness: a global perspective. Bull WHO 2001;79:214-221.

17. Módis L Jr, Szalai E, Facskó A, et al. Corneal transplantation in Hungary (1946-2009). Clin Exper Ophthalmol 2011;39(6):520-525.

18. Fasolo A, Capuzzo C, the CORTES Study Group. Risk Factors for Graft Failure After Penetrating Keratoplasty: 5-Year Follow-Up From the Corneal Transplant Epidemiological Study. Cornea 2011;30:1328-1335.

19. Cornea Donor Study Investigator Group. The effect of donor age on corneal transplantation outcome: results of the cornea donor study. Ophthalmology 2008;115:620-626.

20. Li JY, Mannis MJ. Eye banking and the changing trends in contemporary corneal surgery. Int Ophthalmol Clin 2010;50(3):101-112.

21. Niziol LM, Musch DC, Gillesipe BW, et al. Long-Term Outcomes in Patients Who Received a Corneal Graft for Keratoconus Between 1980 and 1986. Am J Ophthalmol 2013;155(2):213-219.

22. Basu S, Reddy JC, Vaddavalli PK, et al. Long-term Outcomes of Penetrating Keratoplasty for Keratoconus With Resolved Corneal Hydrops. Cornea 2012;31(6):615-620. 